\title{
Correction to: Investigation of Neuregulin-1 and Glial Cell-Derived Neurotrophic Factor in Rodent Astrocytes and Microglia
}

\author{
Jessica Kronenberg ${ }^{1,2} \cdot$ Lukas Merkel $^{1} \cdot$ Sandra Heckers ${ }^{1,2} \cdot$ Viktoria Gudi $^{1} \cdot$ Markus H. Schwab $^{2,3} \cdot$ Martin Stangel $^{1,2}$ (D)
}

Published online: 5 April 2019

(C) Springer Science+Business Media, LLC, part of Springer Nature 2019

Correction to: J Mol Neurosci (2019) 67:484-493

https://doi.org/10.1007/s12031-019-1258-8

The original version of this article unfortunately contained mistakes in the author group and affiliation sections. Author Markus H. Schwab's name was incorrectly presented as "H. Markus Schwab" and his affiliations were incorrectly assigned as "1 and 3" instead of "2 and 3".

Publisher's Note Springer Nature remains neutral with regard to jurisdictional claims in published maps and institutional affiliations.

The online version of the original article can be found at https://doi.org/ 10.1007/s12031-019-1258-8

Martin Stangel

Stangel.martin@mh-hannover.de

1 Clinical Neuroimmunology and Neurochemistry, Department of Neurology, Hannover Medical School, Carl-Neuberg-Str. 1, 30625 Hannover, Germany

2 Center for Systems Neuroscience, University of Veterinary Medicine Hannover, 30559 Hannover, Germany

3 Cellular Neurophysiology, Center of Physiology, Hannover Medical School, 30625 Hannover, Germany 